\title{
A Dinâmica da Taxa de Lucro, da Taxa de Juros e do Grau de Utilização da Capacidade Produtiva em um Modelo Pós-Keynesiano
}

- luciano dias de Carvalho*

\author{
- JOSÉ LUÍS OREIRO **
}

\begin{abstract}
RESUMO
O objetivo do presente artigo é analisar, por meio de simulação computacional, as trajetórias dinâmicas da taxa de acumulação de capital, da taxa de lucro, da taxa de juros e do grau de utilização da capacidade diante de mudanças exógenas do ritmo do progresso tecnológico e da propensão a poupar dos capitalistas. A simulação foi realizada a partir de um modelo macrodinâmico pós-keynesiano que leva em consideração a interação entre o lado real e monetário da economia. Dentre outros resultados, as simulações mostraram que: (i) a taxa de lucro é significativamente elástica com relação a um choque tecnológico positivo, ao passo que a taxa de juros e o grau de utilização da capacidade são pouco sensíveis a esse tipo de choque; e (ii) a confirmação do paradoxo da frugalidade, segundo o qual o aumento da propensão a poupar dos capitalistas acaba por reduzir o nível da poupança agregada, a taxa de lucro e o grau de utilização da capacidade.
\end{abstract}

\section{Palavras-CHave}

modelos macrodinâmicos, teoria pós-keynesiana, simulação computacional

\begin{abstract}
The objective of this paper is to analyze the dynamic path of the profit rate, the interest rate, the rate of capital accumulation and the degree of utilization of the productive capacity - face exogenous changes of the intensity of technological progress and the propensity to save of capitalists within a Post-Keynesian macroeconomic dynamic model that join the real and monetary side of the economy. The computational simulation allowed investigating the degree of proximity of the model to the dynamics of a real economy. The simulation showed, amongst other results, that: (i) the profit rate is significantly elastic with regard to the rate of technological progress, while the interests rate and the degree of utilization of the capacity are little sensible to this variable; and (ii) the confirmation of the paradox of the thrift, according to which an increase of the propensity to save of the capitalists reduces the level of the aggregate saving.
\end{abstract}

\section{KEY WORDS}

macroeconomic dynamic models, post-keynesian theory, computational simulation

\author{
JEL Classification
}

EI2, E5I, E22, O3I, O42

\footnotetext{
* Professor Assistente do Departamento de Economia da UNIOESTE/Francisco Beltrão. Doutorando em Desenvolvimento Econômico pela Universidade Federal do Paraná (UFPR). E-mails: lucianodc@gmail.com e luciano.dc@hotmail.com.br.

** Doutor em Economia (IE/UFRJ), Professor Adjunto do Departamento de Economia da Universidade Federal do Paraná (PPGDE-UFPR) e Pesquisador do CNPq. E-mail: joreiro@ufpr.br e Web-Page: www.joseluisoreiro.ecn.br. (Recebido em fevereiro de 2006. Aceito para publicação em abril de 2007).
} 


\section{INTRODUÇÃO}

Factual work and theoretical work, in an endless relation of give and take, naturally testing one another and setting new tasks for each other, will eventually produce scientific models, the provisional joint products of their interaction with the surviving elements of the original vision, to which increasingly more rigorous standards of consistency and adequacy will be applied.

Schumpeter (1954, p. 42)

O objetivo do presente trabalho é analisar as trajetórias dinâmicas do grau de utilização da capacidade, da taxa de acumulação de capital, da taxa de lucro e da taxa de juros em face de mudanças exógenas do ritmo de progresso tecnológico e da propensão a poupar dos capitalistas, tendo como base um modelo macrodinâmico pós-keynesiano que integre o lado real e monetário da economia.

Para isso, apresentamos inicialmente um modelo macrodinâmico não-linear cujas características principais, que o diferenciam de seus similares pós-keynesianos, são a grande importância dada ao progresso tecnológico para a determinação da dinâmica de longo prazo da economia e, principalmente, a forma pela qual a endogeneidade monetária é especificada.

De fato, o mark-up bancário é suposto aqui como dependendo da taxa de progresso tecnológico. A explicação para essa especificação incomum aos modelos pós-keynesianos é a suposição de que o mark-up bancário é determinado pela preferência pela liquidez dos bancos, de acordo com a assim chamada visão estruturalista da endogeneidade da oferta de moeda (cf. Pollin, 1991). Mudanças na posição de liquidez dos bancos são uma consequiência direta do aumento da demanda por finance, devido ao crescimento dos gastos com investimentos, já que um fluxo constante de investimento pode ser atendido por um fundo rotativo (revolving fund) de ativos líquidos sob a administração dos bancos comerciais (cf. Keynes, 1973, p. 219-220.). ${ }^{1}$ Uma vez que o aumento do investimento é uma consequiência direta do progresso tecnológico, pode-se usar a taxa de progresso tecnológico como uma proxy para a taxa em que o investimento aumenta ao longo do tempo.

1 Nas palavras de Keynes: "I return to the point that finance is a revolving fund. In the main the flow of new finance required by current ex ante investment is provided by the finance released by current ex post investment. When the flow of investment is at a steady rate, so that the flow of ex ante investment is equal to the flow of ex post investment, the whole of it can be provided without any change in the liquidity position. But when the rate of investment is changing in the sense that the current rate of ex ante investment is not equal to the current rate of ex post investment, the question needs further consideration" (1973, p. 219-220). 
Desse modo, quando a taxa de progresso tecnológico se eleva, aumenta consigo a taxa de mark-up cobrada pelos bancos sobre a taxa básica de juros. Esta, por sua vez, é usada pela autoridade monetária como instrumento de controle inflacionário, visto que se supõe a inexistência de outros instrumentos de política monetária. ${ }^{2}$ Desta forma, sempre que ocorrer um aumento da taxa de progresso tecnológico e/ou da taxa de variação dos preços aumentará em conseqüência a taxa de juros cobrada pelos bancos.

O aumento da taxa de juros cobrada pelos bancos em reação ao aumento da demanda por crédito para a introdução de inovações tecnológicas faz com que nos afastemos da concepção horizontalista da oferta de moeda - hipótese Kaldor-Moore - em favor da concepção estruturalista da endogenia monetária.

A distinção fundamental entre a concepção estruturalista com relação à horizontalista é que esta se baseia na concepção de que a curva de oferta de moeda é horizontal no plano juros quantidade de moeda -, de tal forma que a oferta de moeda se adapta plenamente à sua demanda, não havendo, portanto, nenhuma restrição quantitativa com relação à oferta de crédito por parte dos bancos comerciais.

Diferentemente desta concepção, a visão dita estruturalista enfatiza a parcialidade da oferta de moeda. Essa parcialidade advém do fato de o Banco Central não fornecer automaticamente os fundos desejados pelos bancos comerciais ou, quando o faz, oferece tais fundos a uma taxa de redesconto punitiva, ${ }^{3}$ o que leva a uma tendência de alta da taxa de juros na medida em que se eleva a demanda por crédito. (Fiocca, 2000, p. 79)

Com relação à estrutura do artigo, optou-se por dividi-lo em sete seções, incluindo esta breve introdução. Na seção dois apresentamos, por meio de cinco blocos, a estrutura do modelo que será usado para a simulação. Na seção três descrevemos os desdobramentos do modelo no curto e longo prazos. Na seção quatro definimos a dinâmica padrão contra a qual se fará o estudo de dinâmica comparativa. Após isto, nas seções cinco e seis apresentamos as análises de impulso-resposta com relação, respectivamente, à influência dos choques tecnológicos e da propensão a poupar dos capitalistas sobre a trajetória dinâmica de quatro macrovariáveis-chave. Por fim, na seção sete apresentamos as considerações finais do artigo.

2 Mais especificamente, supõe-se que a autoridade monetária não exerça controle sobre a quantidade de moeda.

3 Para a visão estruturalista da oferta de moeda, os bancos, como qualquer outro agente, possuem preferência pela liquidez e buscam, dentro dos limites de uma economia monetária, obter a mais alta margem de lucro possível. Além disso, a autoridade monetária não necessariamente acomoda toda concessão de crédito feita pelos bancos, visto que a possibilidade de crise sistêmica - tão importante para a defesa da concepção horizontalista -, embora exista, seja vista como um evento raro na história do sistema capitalista. 


\section{OS BLOCOS FUNDAMENTAIS DO MODELO PARA SIMULAÇÃO}

O presente modelo busca incorporar dentro da estrutura teórica dos modelos de crescimento econômico e de distribuição funcional da renda da "Escola de Cambridge" elementos teóricos contidos no conceito de economia monetária de produção ${ }^{4}$, notadamente no que tange à concepção endógena da oferta de moeda.

Com efeito, o modelo compartilha com os trabalhos de You (1994), Jarsulic (1989), Watanabe (1997), Dutt (1989 e 1992), Dutt e Amadeo (1993) e Lima e Meirelles (2003) a preocupação em integrar, em um mesmo arcabouço teórico, o lado real e monetário da economia. Mais especificamente, o modelo adota a visão dita estruturalista da oferta de moeda, na qual esta é concebida como sendo parcialmente endógena.

Dentre os modelos de integração com oferta de moeda parcialmente endógena, o presente modelo oferece uma contribuição original ao incorporar a visão schumpeteriana da importância do crédito para a introdução de inovações tecnológicas. Ademais, o modelo incorpora o processo inflacionário como decorrência do conflito de classes, a determinação de preços através de um mark-up sobre os custos unitários de produção e o progresso tecnológico como comportamento defensivo das firmas contra o aumento dos custos da mão-de-obra ou, ainda, como resposta à perda da parcela da renda que cabe à classe capitalista.

O modelo será apresentado através de cinco subsistemas, ou blocos, de forma a facilitar o entendimento da sua estrutura e, também, para sistematizar sua futura ampliação.

\subsection{Preços e Produção $0^{5}$}

Suponhamos uma economia fechada, na qual firmas oligopolistas financiadas por bancos também oligopolistas produzem, através da seguinte função de Leontief, um único bem utilizável tanto para consumo quanto para investimentos:

$$
Q=\min \left[K u_{k} ; L / a\right]
$$

Onde: $Q$ é o nível do produto; $K$ é o estoque de capital; ${ }^{6} u_{k} \equiv Q^{*} / K$ é a relação produto potencial-capital; $L$ é o nível de emprego e $a$ é a relação trabalho-produto $(L / Q)$.

4 Para maiores detalhes sobre o conceito de economia monetária de produção, ver Davidson (1978) e Carvalho (1992).

5 As três primeiras subseções baseiam-se em Lima (1999).

6 Por simplificação, considera-se a ausência de depreciação do capital. 
A inexistência de contratos de longa duração ou de custos de demissão, contratação e treinamento de mão-de-obra permitem que as firmas utilizem a mão-de-obra na exata medida de suas necessidades representadas, dada a relação trabalho-produto, pela demanda por seu produto. Dessa forma, o nível de emprego pode ser apresentado pela seguinte equação: ${ }^{7}$

$$
L=a Q
$$

Isto implica que, dada a relação trabalho-produto, para cada nível de produção existe um único e ótimo nível correspondente de emprego.

Devido à existência de firmas oligopolistas, a variação dos preços se dará sempre que o mark-up desejado for maior que o mark-up efetivo. A equação (7) nos informa que dada a produtividade do trabalho ou igualmente a relação trabalho-produto, o markup efetivo é inversamente relacionado com a parcela salarial de maneira que o hiato existente entre o mark-up desejado e o efetivo pode ser representado pela diferença entre a parcela salarial efetiva e a parcela salarial determinada pelo mark-up desejado. Formalmente, temos:

$$
\hat{\mathrm{P}}=\rho\left[\sigma-\sigma_{f}\right]
$$

Sendo: $\hat{\mathrm{P}}$ a taxa proporcional de variação no preço $(d P / d t)(1 / P) ; \rho$ um parâmetro de sensibilidade e $\sigma_{f}$ a parcela salarial determinada pelo mark-up desejado. Baseandose em Kalecki (1971), o preço cobrado pela firma é determinado por meio da definição de um mark-up, $Z_{f}$, sobre os custos primários de produção. Matematicamente, temos:

$$
\mathrm{P}=\left(1+\mathrm{Z}_{f}\right) W \cdot q
$$

A parcela salarial determinada pelo mark-up desejado pela firma $\left(\sigma_{f}\right)$ depende inversamente do grau de aquecimento no mercado de bens, sendo expressa pela seguinte equação:

$$
\sigma_{f}=\theta-\phi u
$$

Em que: $Z_{f}$ é o mark-up da firma, $\theta$ e $\phi$ são parâmetros positivos.

7 Nesse modelo, supomos que a economia opera com excesso de capacidade em termos de capital, o que a impede de alcançar sua produção potencial. 


\subsection{Distribuição Funcional da Renda}

A renda agregada dessa economia pode ser vista como a soma da remuneração dos trabalhadores, ou seja, do produto do salário real com a quantidade de trabalho empregado e com a rentabilidade do capital utilizado na produção, entendido como o valor de retorno do estoque de capital. Dessa forma, a divisão funcional da renda é dada por:

$$
Q=V L+r K
$$

Sendo $V \equiv W / P$ o salário real; $W$ o salário nominal e $P$ o nível de preços. E onde $r \equiv R / P K$, ou seja, a taxa de lucros $(r)$ definida como o fluxo monetário de lucros $(R)$ dividido pelo estoque de capital $(K)$ valorado pelo nível de preço do produto $(P)$. Usando as equações (2), (6), (8) e (9), acha-se a seguinte expressão da parcela salarial:

$$
\sigma=V \cdot a
$$

A parcela salarial assume valores entre 0 e 1 , mais precisamente $0<\sigma<1$, de forma que a parcela dos lucros na renda $(m)$ pode ser escrita da seguinte forma:

$$
m=1-\sigma
$$

A taxa de lucro pode ser expressa em função da parcela salarial e do grau de utilização da capacidade produtiva. Mais precisamente, temos:

$$
r=m \cdot u
$$

Onde: $u$ é o grau de utilização da capacidade, $u=Q / Q^{*}$.

\subsection{Mercado de Trabalho}

A taxa proporcional de variação do salário nominal cresce com o passar do tempo de acordo com o hiato entre a parcela salarial desejada pelos trabalhadores $\left(\sigma_{W}\right)$ e a parcela efetiva $(\sigma)$, ponderados positivamente pelo parâmetro de sensibilidade $(\lambda)$, como demonstrado pela seguinte equação:

$$
\hat{W}=\lambda\left[\sigma_{W}-\sigma\right]
$$


A parcela salarial desejada pelos trabalhadores será tanto maior quanto maior for o poder de barganha dos trabalhadores vis-à-vis ao dos capitalistas. Esse poder de barganha, por seu lado, aumentará sempre que a taxa de emprego aumentar. Formalmente, temos:

$$
\sigma_{W}=\varepsilon E
$$

Sendo: $\varepsilon$ um parâmetro de sensibilidade positivo e $E$ a taxa de emprego - entendida como a razão entre o nível de emprego e a oferta de emprego $(L / N)$. A taxa de emprego está relacionada ao mercado de bens segundo a seguinte relação funcional:

$$
E=u . k
$$

Onde: $k$ é a razão entre o estoque de capital e a oferta de trabalho em unidades de produtividade, como demonstrado na equação (13) abaixo:

$$
k=K /(N / a)
$$

A taxa de crescimento proporcional da oferta de trabalho é aqui modelada como aumentando a uma taxa exógena $\eta$, ou seja:

$$
\hat{N}=\eta
$$

\subsection{Mercado Financeiro}

A taxa básica de juros $\left(i^{B}\right)$ é utilizada pela autoridade monetária como instrumento de controle inflacionário. Sempre que a taxa de inflação aumentar, a autoridade monetária elevará pari passu a taxa básica de juros como forma de conter o aumento da inflação. Formalmente, temos:

$$
i^{B}=\varphi \cdot \hat{\mathrm{P}}
$$

Onde: $\phi$ é um parâmetro positivo de sensibilidade da taxa básica de juros com relação à taxa de inflação.

A taxa de juros $i$ dessa economia é determinada por meio de um mark-up bancário $\left(Z_{B}\right)$ sobre a taxa básica de juros administrada pelo Banco Central $\left(i^{B}\right)$, como pode ser evidenciado pela seguinte equação: 


$$
i=\mathrm{Z}_{B} i^{B}
$$

O mark-up bancário é aqui modelado como uma função direta da taxa de progresso tecnológico, uma vez que um aumento da taxa de inovação tecnológica irá induzir as firmas a aumentar os seus gastos planejados de investimento, gerando consigo um aumento da demanda por finance. ${ }^{8}$ Essa demanda crescente de finance gera uma redução da posição de liquidez dos bancos, induzindo assim um aumento do mark-up bancário. Essa relação é formalmente denotada como segue:

$$
\mathrm{Z}_{B}=\mu . \hat{\Gamma}
$$

Sendo $\mu$ um parâmetro positivo de sensibilidade do mark-up bancário com relação à demanda por crédito, vale dizer, com relação à taxa de progresso tecnológico.

\subsection{Acumulação de Capital e Progresso Tecnológico}

Os planos de acumulação da firma podem ser descritos pela seguinte relação funcional: ${ }^{9}$

$$
{\frac{I^{d}}{K}}^{d}=\alpha+\beta(r-i)+\tau \cdot \hat{\Gamma}
$$

Onde: $\frac{I^{d}}{K}$ é a acumulação desejada das firmas como fração do estoque de capital, $\alpha$ é o parâmetro (positivo) autônomo de acumulação, $\beta$ e $\tau$ são, respectivamente, parâmetros positivos de sensibilidade do diferencial da taxa de lucro $r$ com a taxa de juros bancária $i$ e da taxa de inovação tecnológica poupadora de mão-de-obra $\hat{\Gamma}$.

A taxa de inovação tecnológica, por sua vez, é definida como sendo influenciada positivamente pela parcela salarial por meio da ponderação do parâmetro de sensibilidade $\psi$, como mostrado abaixo:

8 Para Schumpeter (1934) o crédito bancário tem um importante papel na viabilização do processo de acumulação de capital através do adiantamento de recursos monetários que só serão gerados ex post ao processo de inovação. Para interessante discussão entre a visão do papel da moeda nas teorias de Schumpeter e Keynes, ver Vercelli (1991).

9 Desta forma diferenciamos, dentre outros, de Lima (1999), Rowthorn (1981) e Dutt (1984 e 1990). Ademais, o argumento dessa função investimento pode ser balizado nos trabalhos de Dutt (1994), que se apóia na idéia de Kalecki (1971) da existência de uma correlação positiva entre progresso tecnológico e investimento; de Schumpeter (1934), de que o processo de inovação acaba, com o tempo, se espraiando para toda economia e, por fim, em Nelson e Winter (1982), cujo processo de investimento é fortemente condicionado pela dinâmica de progresso tecnológico. 


$$
\hat{\Gamma}=\psi \cdot \sigma
$$

No curto prazo, a relação trabalho-produto $a$ é fixa. Porém, no longo prazo, ela diminuirá na medida em que aumentar a taxa de inovação tecnológica $\hat{\Gamma}$, ou seja:

$$
\hat{a}=-\psi \cdot \sigma
$$

Onde $\hat{a}$ é a taxa de variação proporcional da relação trabalho-produto.

Como as firmas operam com excesso de capacidade em termos de capital, elas ajustam os seus graus de utilização da capacidade de forma a produzir na exata medida para atender a demanda efetiva. Equalizando dessa forma, o investimento desejado e a poupança segundo a seguinte equação:

$$
\frac{I}{K}=s r
$$

Onde: $\frac{I}{K} \equiv \frac{\partial K}{K}$ é a taxa de crescimento proporcional do estoque de capital e $s$ a propensão marginal a poupar dos capitalistas.

\section{OS DESDOBRAMENTOS DO MODELO NO CURTO E LONGO PRAZOS}

No equilíbrio de curto prazo, variações no grau de utilização da capacidade produtiva farão com que a taxa de crescimento proporcional do estoque de capital seja igual à taxa proporcional de acumulação desejada das firmas, ou seja: $\frac{I}{K}=\frac{I}{K}^{d}$.

Usando as equações (3), (5), (8), (9), (15), (16), (17), (18), (19) e (21), pode-se determinar o valor de equilíbrio de curto prazo do grau de utilização da capacidade $\left(u^{*}\right)$ como segue:

$$
u^{*}=\frac{-A \cdot \sigma^{2}+B \cdot \sigma+\alpha}{(s-\beta)(1-\sigma)+C \cdot \sigma}
$$

Sendo: $A \equiv \beta \mu \varphi \psi \rho ; B \equiv \beta \mu \varphi \psi \rho \theta+\tau \psi$ е $C \equiv \beta \mu \varphi \psi \rho \phi$.

A taxa de juros bancária sofre uma influência conjunta da taxa do progresso tecnológico e da taxa básica de juros. Esta última, por sua vez, é influenciada pela taxa de 
inflação e pelo grau de utilização da capacidade de equilíbrio. Em vista disso, a taxa de juros cobrada pelos bancos comporta-se de acordo com a seguinte expressão:

$$
i=(\mu \varphi \psi \rho) \cdot \sigma^{2}-(\mu \varphi \psi \rho \theta) \cdot \sigma+(\mu \varphi \psi \rho \phi) u . \sigma
$$

Ao substituirmos nessa equação o grau de utilização da capacidade de equilíbrio, equação (22), podemos perceber o comportamento da taxa de juros bancária de equilíbrio, isto é, da taxa de juros compatível com o equilíbrio entre a taxa desejada de acumulação das firmas e a taxa de crescimento do estoque de capital. Tal comportamento se dá de acordo com a seguinte equação:

$$
i^{*}=\frac{\Psi \cdot \sigma^{3}+\chi \cdot \sigma^{2}+\pi \cdot \sigma}{(s-\beta)(1-\sigma)+C \cdot \sigma}
$$

Onde: $\Psi \equiv C(\mu \varphi \psi \rho)-(\mu \varphi \psi \rho)(s-\beta)-A(\mu \varphi \psi \rho \phi) ; \chi \equiv(\mu \varphi \psi \rho \theta)(s-\beta)+B(\mu \varphi \psi \rho \phi)$ $-C(\mu \varphi \psi \rho \theta)$

$$
\pi \equiv(\alpha \mu \varphi \psi \rho \phi)-(\mu \varphi \psi \rho \theta)(s-\beta)
$$

A taxa de crescimento da economia no equilíbrio $\left(\frac{I}{K}^{*}\right)$ pode ser encontrada utilizando-se as equações (8), (9), (21) e (22):

$$
\frac{I}{K}^{*}=\frac{s A \cdot \sigma^{3}-H \cdot \sigma^{2}+M \cdot \sigma+s \alpha}{(s-\beta)(1-\sigma)+C \sigma}
$$

Sendo: $H \equiv s(A+B)$ e $M \equiv s(B-\alpha)$

A taxa de lucro compatível com o equilíbrio entre a taxa de investimento desejada e efetiva é determinada ao se substituir as equações (8) e (22) em (9). A partir dessas substituições obtém-se a seguinte equação que descreve a taxa de lucro de equilíbrio:

$$
r^{*}=\frac{A \cdot \sigma^{3}-(A+B) \sigma^{2}+(B-\alpha) \sigma+\alpha}{(s-\beta)(1-\sigma)+C \sigma}
$$

No longo prazo, a economia se move devido a variações no estoque de capital, na oferta de trabalho, na relação trabalho-produto, no nível de preço e no salário nominal, com o grau de utilização da capacidade, a taxa de acumulação e a taxa de juros bancária sempre em equilíbrio. 
A partir das seguintes definições da parcela salarial $\sigma \equiv V q$ e da razão entre o estoque de capital e a oferta de trabalho em unidades de produtividade $k \equiv K /(N / q)$, podemos acompanhar o comportamento dinâmico do sistema.

Linearizando ambas as equações e derivando-as em relação ao tempo, chegamos ao seguinte sistema bidimensional de equações diferenciais não-lineares: ${ }^{10}$

$$
\begin{aligned}
& \hat{\sigma}=\hat{W}-\hat{\mathrm{P}}+\hat{q} \\
& \hat{k}=\hat{K}+\hat{a}-\hat{N}
\end{aligned}
$$

Onde: $\hat{a}=\partial \sigma / \sigma ; \hat{k}=\partial k / K$ e assim por diante.

Substituindo as equações (3), (5), (10), (11), (12) e (20) na equação (28), podemos apresentar a taxa de variação proporcional da parcela salarial, em função do estoque de capital em unidades de oferta de trabalho eficiente $(k)$ e do grau de utilização da capacidade produtiva de equilíbrio $\left(u^{*}\right)$ que, por sua vez, encontra-se unicamente em função da parcela salarial $\sigma$. Sendo assim, temos que:

$$
\hat{\sigma}=u^{*}[(\lambda \varepsilon) k-\rho \phi]-(\lambda+\psi+\rho) \sigma+\rho \theta
$$

Sabemos que: $I \equiv \frac{\partial K}{\partial t} \Rightarrow \frac{I}{K} \equiv \hat{K} \equiv s r=s(1-\sigma) u$. Ao substituir essa equação juntamente com as equações (14) e (20) na equação (29), pode-se apresentar a taxa de variação proporcional do estoque de capital em unidades de oferta de trabalho eficiente $(\hat{k})$ em função de $\sigma$, como demonstra a equação (31):

$$
\hat{k}=\frac{s A \cdot \sigma^{3}+\Omega \cdot \sigma^{2}+\Sigma \cdot \sigma+\Lambda}{(s-\beta)(1-\sigma)+C \cdot \sigma}
$$

Onde: $\Omega \equiv C \psi-H-\psi(s-\beta) ; \Sigma \equiv J+\eta C+\psi(s-\beta)-\eta(s-\beta) ; \Lambda \equiv s \alpha+\eta(s-\beta)$ e $\eta$ é a taxa positiva de crescimento exógena da força de trabalho.

Diante disto, temos um sistema bidimensional de equações diferenciais não-lineares $\hat{\sigma}$ e $\hat{k}$ que descrevem, respectivamente, o comportamento da parcela salarial $(\sigma)$ e do estoque de capital em unidades de oferta eficiente de trabalho $(k)$ ao longo do tempo. ${ }^{11}$ A partir dessas duas equações diferenciais e das equações de equilíbrio das

10 Lembrando que $V \equiv W / P$.

11 Uma análise de uma possível configuração de equilíbrio do modelo é apresentada no Anexo-I. 
macrovariáveis determinadas acima, é possível realizar o exercício proposto de dinâmica comparativa. Vamos agora nos ater a ele.

\section{DEFININDO A DINÂMICA PADRÃO}

O processo de simulação computacional tem um duplo propósito: (i) analisar as propriedades práticas de um modelo teórico, verificando os valores de equilíbrio para as variáveis macroeconômicas em estudo e (ii) evidenciar as grandezas numéricas envolvidas nas trajetórias dinâmicas especificadas pela análise teórico-qualitativa.

A grande vantagem de uma análise numérica por meio da simulação computacional consiste em verificar até que ponto as condições tidas como teoricamente possíveis na análise teórico-qualitativa permanecem plausíveis ou realistas na análise numérica. Ou seja, é possível que os resultados práticos de um modelo teórico estejam - a despeito de sua análise qualitativa - incorretos quando confrontados com os valores paramétricos do mundo real, o que nos arremete à necessidade de se efetuar análises empíricas (numéricas) nos modelos teóricos com soluções gerais ${ }^{12}$ - como observado por Schumpeter na epígrafe do presente artigo.

Tendo em vista satisfazer a essa necessidade, adequamos o modelo teórico, deduzido na seção anterior, para o exercício numérico de dinâmica comparativa. Para tanto, utilizamos as equações diferenciais e de equilíbrio para simular em computador as trajetórias no tempo das quatro macrovariáveis em estudo. Nesse contexto, os parâmetros do modelo foram inicialmente calibrados ${ }^{13}$ de forma a obter um conjunto de trajetórias e de valores de equilíbrio de longo prazo que estivessem de acordo com a realidade do sistema econômico em estudo. ${ }^{14}$ A esse conjunto de trajetórias derivadas dos valores paramétricos iniciais chamamos de dinâmica padrão.

12 Para uma discussão sobre a metodologia de simulação, ver: Hansen e Heckman (1996), Kydland e Prescott (1996).

13 Durante o processo de calibração é possível (e provável) que inexistam valores contábeis ou evidências empíricas para alguns dos parâmetros do modelo. Nesse caso, para contornar a existência de parâmetros livres, utiliza-se o princípio da correspondência de Samuelson. Tal princípio consiste em atribuir arbitrariamente os valores paramétricos necessários para que se consiga descrever, com o mais alto grau de realismo possível, o movimento de um sistema econômico complexo.

14 O procedimento de calibração do modelo pode ser assim sistematizado. Primeiro, escolhe-se um conjunto inicial de valores paramétricos buscando, sempre que possível, se apoiar em dados contabilizados e/ou estimados empiricamente. Em seguida, "roda-se" o programa e obtêm-se as trajetórias dinâmicas das variáveis endógenas relevantes para o estudo. Posteriormente, como terceiro procedimento, comparam-se as trajetórias obtidas (e os valores de equilíbrio de longo prazo) com as evidências empíricas ou o que se considera como "fatos estilizados" da economia em estudo. E, caso as trajetórias obtidas sejam pouco "aderentes" à realidade, escolhe-se um novo conjunto de parâmetros (e/ou condiçóes iniciais) e repete-se o experimento. 
Desse modo, o ponto inicial para o estudo foi a definição da dinâmica padrão contra a qual se fez a análise de dinâmica comparativa. Assim, definimos os valores para todos os parâmetros do modelo buscando, sempre que possível, ancorar tais escolhas em evidências empíricas e/ou em estudos contábeis. A Tabela l a seguir apresenta os parâmetros com seus respectivos valores e o papel que eles desempenham no modelo.

\section{TABELA I - PARÂMETROS E VALORES REFERENTES À DINÂMICA PADR ÂO}

\begin{tabular}{|c|c|c|}
\hline Parâmetro & Valor & Descrição \\
\hline$\alpha$ & 0,01 & Propensão autônoma a investir ou animal spirits dos investidores. \\
\hline$s$ & 0,80 & Propensão a poupar dos capitalistas. \\
\hline$\beta$ & 0,75 & $\begin{array}{l}\text { Coeficiente que capta a sensibilidade do investimento desejado ao diferencial entre a taxa de } \\
\text { lucro e a taxa de juros bancária. }\end{array}$ \\
\hline$\tau$ & 0,25 & $\begin{array}{l}\text { Coeficiente que capta a sensibilidade do investimento desejado a variações no progresso tec- } \\
\text { nológico. }\end{array}$ \\
\hline$\psi$ & 0,03 & $\begin{array}{l}\text { Coeficiente que capta a sensibilidade do progresso tecnológico com relação a variações na } \\
\text { parcela salarial. }\end{array}$ \\
\hline$\rho$ & 1,10 & $\begin{array}{l}\text { Coeficiente que capta a sensibilidade da taxa de variação dos preços com relação à diferença } \\
\text { entre a parcela salarial efetiva e a determinada pelo mark-up desejado das firmas. }\end{array}$ \\
\hline$\theta$ & 0,40 & $\begin{array}{l}\text { Parâmetro que mede o componente autônomo da parcela salarial determinada do mark-up } \\
\text { desejado das firmas. }\end{array}$ \\
\hline$\varphi$ & 0,70 & $\begin{array}{l}\text { Coeficiente que capta a influência do grau de utilização da capacidade produtiva sobre a par- } \\
\text { cela salarial implicada pelo mark-up desejado das firmas. }\end{array}$ \\
\hline$\lambda$ & 0,50 & $\begin{array}{l}\text { Coeficiente de sensibilidade da taxa de variação dos salários nominais com relação ao diferen- } \\
\text { cial entre a parcela salarial desejada pelos trabalhadores e a parcela salarial efetiva. }\end{array}$ \\
\hline$\varepsilon$ & 0,025 & $\begin{array}{l}\text { Coeficiente de sensibilidade da parcela salarial desejada pelos trabalhadores com relação à } \\
\text { taxa de emprego. }\end{array}$ \\
\hline$\eta$ & 0,01 & Taxa de crescimento populacional. \\
\hline$\phi$ & 1,50 & $\begin{array}{l}\text { Coeficiente que capta a sensibilidade da taxa básica de juros com respeito à taxa de variação } \\
\text { de preços. }\end{array}$ \\
\hline$\mu$ & 1,15 & Coeficiente que capta a influência do progresso tecnológico sobre a taxa de mark-up bancário. \\
\hline
\end{tabular}

Baseando-se em Kaldor (1993), a propensão a poupar dos capitalistas $s$ foi assumida como sendo de 0,8 . Supomos que essa economia apresenta uma taxa de crescimento populacional, $\eta$ da ordem de $1 \%$ (ou 0,01 ) ao ano. Adotamos para a sensibilidade da taxa básica de juros com respeito à taxa de variação dos preços $\phi$ o valor estimado para a economia brasileira de 1,50. (Blanchard, 1999, p. 359)

Os demais parâmetros do modelo não encontram respaldo nos estudos empíricos, sendo, portanto, parâmetros livres. No entanto, é possível inferir valores plausíveis para esses parâmetros, bastando para isso isolarmos o seu efeito por meio da suposição de que os demais parâmetros que formam a função assumem valores iguais a zero. 
Por exemplo, supomos um valor para a propensão autônoma a investir $(\alpha)$ na ordem de 0,01 . A escolha desse valor implica que ao considerarmos os parâmetros $\beta$ e $\tau$ iguais a zero na equação (18) que especifica o investimento desejado, então a taxa de crescimento do investimento desejado será de $1 \%$ por período, o que se encontra dentro do plausível para uma economia de mercado.

Seguindo esse mesmo procedimento, determinamos os valores para os demais parâmetros. De fato, para o parâmetro que descreve a sensibilidade do progresso tecnológico com relação à parcela salarial $\psi$ admitimos um limite máximo para o crescimento da produtividade do trabalho de $3 \%$. Supondo uma diferença de $10 \%$ entre a parcela salarial desejada pelos trabalhadores e a parcela salarial efetiva $\left(\sigma_{W}-\sigma=0,1\right)$, então a taxa de variação do salário nominal assume valores de $5 \%$, o que sugere o valor de $\lambda=0,5$.

Assumimos uma taxa de sensibilidade dos juros bancários, $\mu$, de 1,15. O que implica supor uma taxa máxima de mark-up bancário de 3,45. Uma taxa de mark-up bancário dessa magnitude equivale a uma taxa de juros bancários 3,45 vezes superior à taxa básica de juros. Esta, por sua vez, é $50 \%$ maior do que a taxa de variação dos preços como demonstrado pelo parâmetro $\phi=1,5$. Por sua vez, analisando o parâmetro $\theta$ da equação (5), que determina a parcela salarial implicada pelo mark-up desejado das firmas $\phi_{f}$ verificamos que este assume um valor mínimo de $40 \%(0,40)$ quando, por hipótese, o grau de utilização produtiva, $u$, cai para um nível igual a zero.

Uma vez definidos os parâmetros que levam o sistema a um equilíbrio satisfatório, e definindo as condições iniciais como $k[0]=0,5$ e $\sigma[0]=0,75$, é possível analisar o comportamento de algumas macrovariáveis-chave. ${ }^{15}$ Para isso, analisamos o comportamento no tempo do grau de utilização da capacidade produtiva $(u)$, da taxa de investimento $(I / K \equiv \partial K / K)$, da taxa de lucro $(r)$, e, por fim, da taxa de juros bancários $(i)$.

A Figura 1 mostra a trajetória no tempo do grau de utilização da capacidade produtiva e da taxa de investimento. Nela, percebe-se que o grau de utilização da capacidade produtiva partindo de um valor inicial igual a $37,96 \%$ se eleva durante 20 períodos até atingir o seu ponto de máximo equivalente ao grau de utilização de aproximadamente $94 \%$, quando então decresce monotonicamente até seu estado estacionário de longo prazo correspondente ao valor de $71,98 \%$ da capacidade. Vale ressaltar que em nenhum momento o grau de utilização da capacidade foi pleno, tendo as firmas sempre mantido certa capacidade excedente na sua trajetória para o equilíbrio de longo prazo. Por seu turno, a taxa de investimento parte de um valor inicial de $2,53 \%$ cres-

15 No Anexo-II é apresentada uma análise da sensibilidade das macrovariáveis em estudo com relação às condições iniciais do modelo. 
cendo a altas taxas durante 45 períodos, quando então alcança seu valor de equilíbrio equivalente a $17,73 \%$.

FIGURA I - A DINÂMICA PADR ÂO PARA $(u) E(g \equiv d K / K)$

(A) GRAU DE UTILIZAÇÃO DA CAPACIDADE (u)

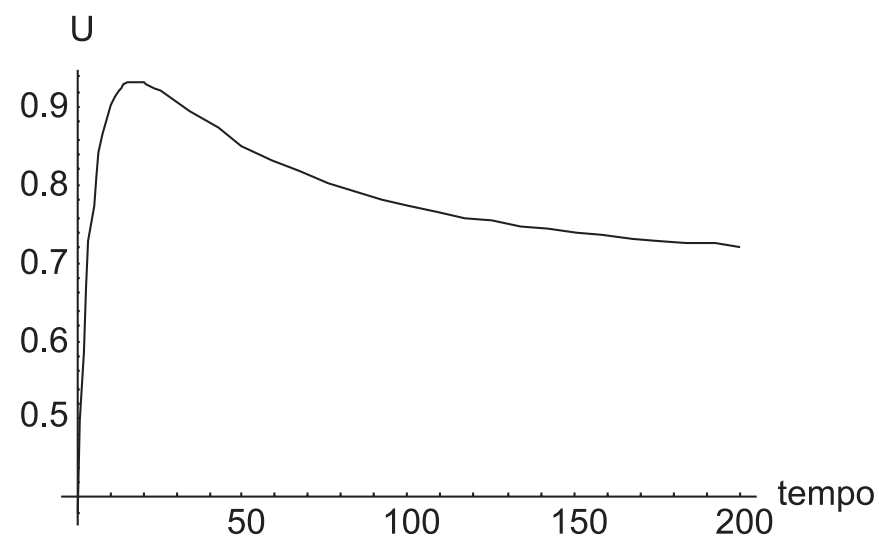

(B) TAXA DE INVESTIMENTO $(g \equiv d K / K)$

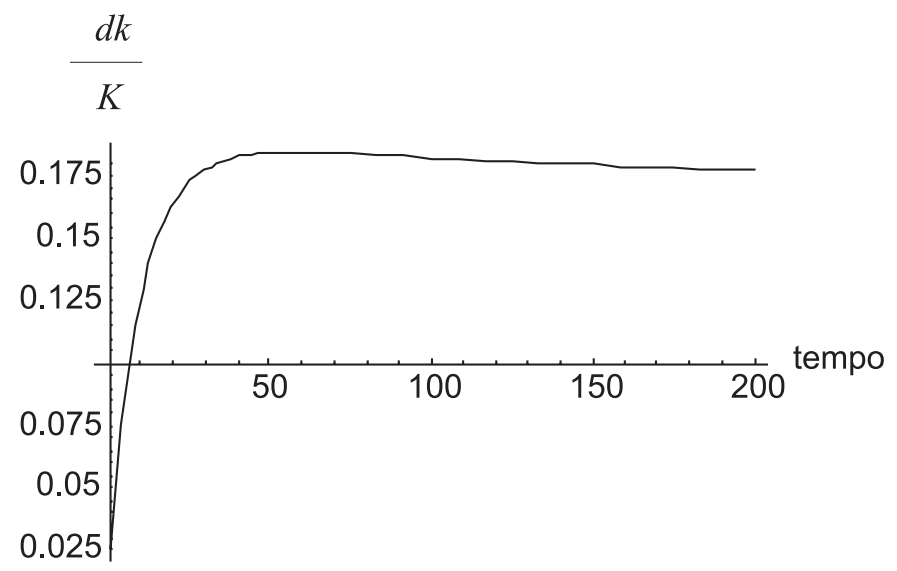

As trajetórias da taxa de lucro e da taxa de juros bancários são mostradas na Figura 2. Por ela, percebe-se que a taxa de lucro, iniciando de um patamar de $3,16 \%$, cresce a taxas decrescentes até atingir no quadragésimo sexto período o seu valor de estado estacionário igual a $22,16 \%$. Por seu turno, a taxa de juros bancários apresenta um 
valor inicial de $24,96 \%$, decrescendo monotonicamente até atingir o seu valor de estado estacionário de $1,93 \%$ no limiar do período de análise.

FIGURA 2 - A DINÂMICA PADR ÁO PARA $(r) E(i)$

(A) TAXA DE LUCRO $(r)$

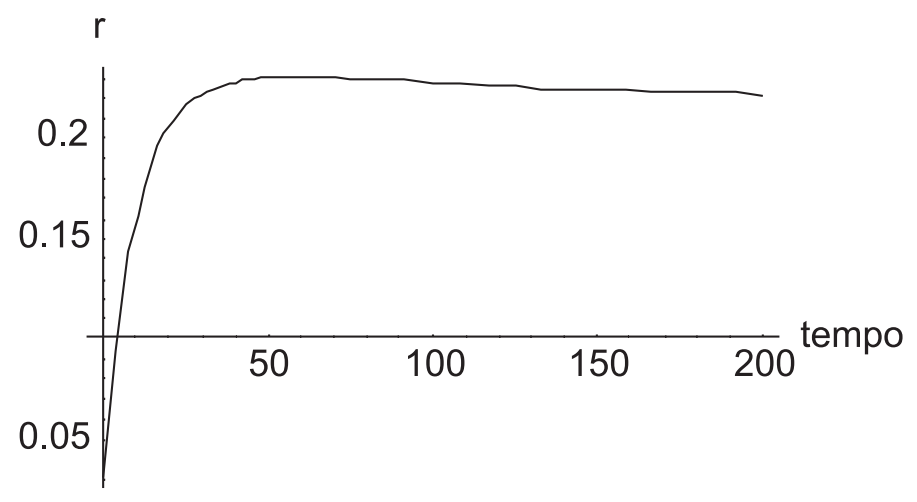

(B) TAXA DE JUROS BANCÁRIA (i)

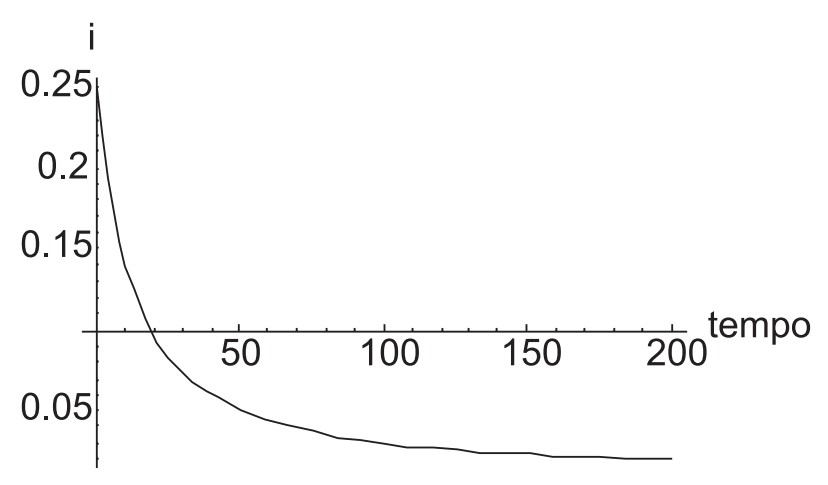

Uma vez que descrevemos o comportamento dinâmico das trajetórias no tempo das principais variáveis relevantes do modelo, cabe questionarmos até que ponto são sólidos os valores dos parâmetros definidos para descrever essas trajetórias. Para analisarmos a robustez dos resultados da simulação, iremos submeter os parâmetros a um 
teste de estresse. Com efeito, variaremos os valores paramétricos iniciais definidos na Tabela 1 de $20 \%$ a $50 \%$, dependendo do parâmetro em estudo.

A Tabela 2 resume os resultados obtidos com o teste, em que os asteriscos contidos em certas células denotam valores economicamente implausíveis. Assim, por exemplo, uma diminuição em $25 \%$ na propensão a poupar $(s)$ faz com que o grau de utilização da capacidade atinja o seu valor de equilíbrio em -86,40\%, o que é impossível ocorrer visto que o grau de utilização da capacidade assume valores positivos compreendidos entre zero e um, ou seja, entre 0 e $100 \%$.

O mesmo vale para a taxa de investimento, que não pode assumir valores negativos uma vez que desconsideramos os efeitos da depreciação do capital; também para a taxa de lucro, visto não ser concebível que a economia opere continuamente com a classe capitalista obtendo um retorno negativo das suas operações.

Por essa tabela, é possível comparar o impacto da variação percentual de cada parâmetro em torno do seu valor inicial sobre as macrovariáveis relevantes do estudo. Com efeito, uma variação em módulo de $25 \%$ da sensibilidade dos preços com relação ao diferencial entre a parcela salarial efetiva e a implicada pelo mark-up desejado das firmas, $\rho$ - que pode ser vista como uma proxy para o poder de mercado destas - mostrou ter pouco impacto sobre o grau de utilização da capacidade, de tal forma que uma variação de $50 \%$ (25\% para mais e $25 \%$ para menos) alterou em apenas $0,42 \%$ o grau de utilização. O mesmo ocorre para as taxas de investimento $(0,27 \%)$, de lucro $(0,3 \%)$ e de juros bancários $(0,715 \%)$.

Por outro lado, a propensão autônoma a investir $(\alpha)$ teve um impacto significativo sobre as variáveis reais com um aumento de $47,75 \%$ do grau de utilização da capacidade, de $16,64 \%$ para a taxa de investimento, de $17,04 \%$ para a taxa de lucro em decorrência de uma variação de $50 \%$ do seu valor. A taxa de juros, entretanto, apresentou pouca sensibilidade $(0,12 \%)$ com relação ao aumento de $50 \%$ da propensão autônoma a investir. 
TABELA 2 - TESTE DE ROBUSTEZ

\begin{tabular}{|c|c|c|c|c|c|}
\hline \multirow[t]{2}{*}{ Parâmetro } & \multirow[t]{2}{*}{ Valor } & \multicolumn{4}{|c|}{ Valores do Equilíbrio de Longo Prazo } \\
\hline & & $u$ & $I / K \equiv d K / K$ & $r$ & $i$ \\
\hline Valores & Ver & 0,7219 & 0,1775 & 0,2215 & 0,0197 \\
\hline Originais & Tabela 1 & & & & \\
\hline \multirow[t]{2}{*}{$\alpha$} & 0,005 & 0,4835 & 0,1110 & 0,1386 & 0,0117 \\
\hline & 0,015 & 0,9610 & 0,2774 & 0,3090 & 0,0129 \\
\hline \multirow[t]{2}{*}{$s$} & 0,60 & $-0,8640^{*}$ & 0,0078 & 0,0130 & 0,6259 \\
\hline & 0,99 & 0,1941 & 0,0541 & 0,0594 & 0,0076 \\
\hline \multirow[t]{2}{*}{$\beta$} & 0,5625 & 0,1905 & 0,0416 & 0,0520 & 0,0077 \\
\hline & 0,9375 & $-1,1518^{*}$ & $-0,0056^{*}$ & $-0,0069^{*}$ & 0,6080 \\
\hline \multirow[t]{2}{*}{$\tau$} & 0,1875 & 0,7121 & 0,1750 & 0,2190 & 0,0195 \\
\hline & 0,3125 & 0,7272 & 0,1793 & 0,2241 & 0,0190 \\
\hline \multirow[t]{2}{*}{$\psi$} & 0,0225 & 0,7030 & 0,1730 & 0,2164 & 0,0200 \\
\hline & 0,0375 & 0,7357 & 0,1813 & 0,2266 & 0,0186 \\
\hline \multirow[t]{2}{*}{$\rho$} & 0,825 & 0,7187 & 0,1761 & 0,2200 & 0,0156 \\
\hline & 1,375 & 0,7229 & 0,1787 & 0,2233 & 0,0228 \\
\hline \multirow[t]{2}{*}{$\theta$} & 0,30 & 0,6638 & 0,1687 & 0,2109 & 0,0119 \\
\hline & 0,50 & 0,7980 & 0,1889 & 0,2361 & 0,0252 \\
\hline \multirow[t]{2}{*}{$\varphi$} & 0,525 & 0,7288 & 0,1794 & 0,2243 & 0,0143 \\
\hline & 0,875 & 0,7111 & 0,1752 & 0,2190 & 0,0241 \\
\hline \multirow[t]{2}{*}{$\lambda$} & 0,375 & 0,7257 & 0,1780 & 0,2224 & 0,0204 \\
\hline & 0,625 & 0,7144 & 0,1767 & 0,2209 & 0,0183 \\
\hline \multirow[t]{2}{*}{$\varepsilon$} & 0,0187 & 0,7191 & 0,1772 & 0,2215 & 0,0192 \\
\hline & 0,0312 & 0,7204 & 0,1773 & 0,2217 & 0,0194 \\
\hline \multirow[t]{2}{*}{$\eta$} & 0,0075 & 0,7197 & 0,1773 & 0,2216 & 0,0193 \\
\hline & 0,0125 & 0,7198 & 0,1773 & 0,2216 & 0,0193 \\
\hline \multirow[t]{2}{*}{$\phi$} & 1,1250 & 0,7508 & 0,1791 & 0,2239 & 0,0206 \\
\hline & 1,8750 & 0,6905 & 0,1745 & 0,2182 & 0,0161 \\
\hline \multirow[t]{2}{*}{$\mu$} & 0,8625 & 0,7107 & 0,1752 & 0,2190 & 0,0145 \\
\hline & 1,4375 & 0,7288 & 0,1793 & 0,2242 & 0,0241 \\
\hline
\end{tabular}

Como era de se esperar, sempre que o coeficiente $\beta$, que capta a sensibilidade do investimento desejado ao diferencial da taxa de lucro com a taxa de juros assumiu valores maiores do que a propensão a poupar $s$, o sistema apresentou uma dinâmica explosiva (depressiva), adquirindo valores de equilíbrio impossíveis. A exceção foi com a taxa de juros $i$, que apresentou uma elevação de $60,03 \%$ em decorrência do aumento de $50 \%$ do valor do coeficiente $\beta$.

Além disso, na medida em que a diferença entre a propensão a poupar dos capitalistas $s$ e o coeficiente $\beta$ se ampliava, houve uma clara tendência depressiva da economia, com o grau de utilização da capacidade assumindo o valor de $19,41 \%$, a taxa de investimento $5,41 \%$, a taxa de lucro $5,94 \%$ e a taxa de juros $0,76 \%$ - como pode ser observado na Tabela 2 - quando $s=0,99$ e $(s-\beta=0,24)$. 
A variação em $50 \%$ do coeficiente de sensibilidade do progresso tecnológico $\psi$ elevou o grau de utilização da capacidade em $3,27 \%$, os investimentos em $0,83 \%$, a taxa de lucro em $1,02 \%$ e a taxa de juros em $0,14 \%$. Por fim, a variação de $50 \%$ do coeficiente que capta a sensibilidade do mark-up bancário com relação ao progresso tecnológico $\mu$ aumentou em aproximadamente $0,96 \%$ a taxa de juros bancária.

Após termos definido o conjunto de parâmetros que geram a dinâmica padrão e discutido o grau de robustez dos valores paramétricos escolhidos e mostrado os efeitos da variação desses valores sobre as macrovariáveis em estudo, iremos agora realizar um exercício de impulso-resposta. Ou seja, iremos alterar ceteris paribus o valor de dois parâmetros considerados chaves para o estudo em curso, a saber, o parâmetro que determina a taxa de progresso tecnológico e o parâmetro que capta a propensão a poupar dos capitalistas, que de certa forma incorpora o grau de confiança que esses agentes possuem com relação ao futuro comportamento da economia.

\section{TESTE DE IMPULSO-RESPOSTA: A INFLUENCIA DOS CHOQUES TECNOLÓ- GICOS}

O primeiro teste de impulso-resposta será feito para analisar o impacto dos choques tecnológicos sobre as trajetórias dinâmicas do sistema econômico em estudo. Com efeito, iremos elevar em $33 \%$ (de 0,03 para 0,04 ) a sensibilidade do parâmetro tecnológico e verificar o impacto que um choque dessa magnitude tem sobre a dinâmica das principais macrovariáveis em estudo.

A Figura 3 apresenta a dinâmica comparada do grau de utilização da capacidade e da taxa de investimento para o nível antigo e novo (em negrito) do parâmetro de sensibilidade do progresso tecnológico $\psi$. De imediato, percebe-se que o choque tecnológico diminuiu o valor inicial do grau de utilização da capacidade, passando de algo em torno de $37,96 \%$ para $18,10 \%$ (diminuição de $19,86 \%$ ). 
FIGURA 3 - IMPACTO DOS CHOQUES TECNOLÓGICOS SOBRE (u) E $(g \equiv d K / K)$

(A) GRAU DE UTILIZAÇÃO DA CAPACIDADE (u) QUANDO $(\psi=0,03) \mathrm{e}$ $\underbrace{(\psi=0,04)}_{\text {"NEGRITO" }}$

U

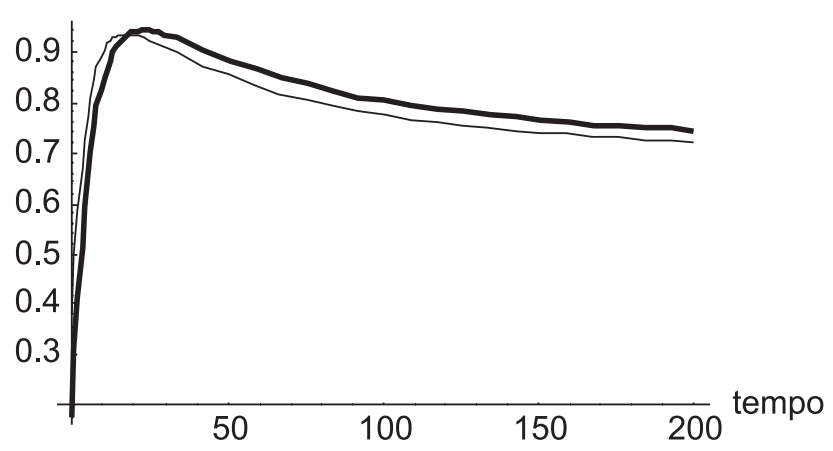

(B) TAXA DE INVESTIMENTO $(g \equiv d K / K) \quad$ QUANDO $\quad(\psi=0,03) \quad \mathrm{e}$ $\underbrace{(\psi=0,04)}_{\text {"NEGRITO" }}$

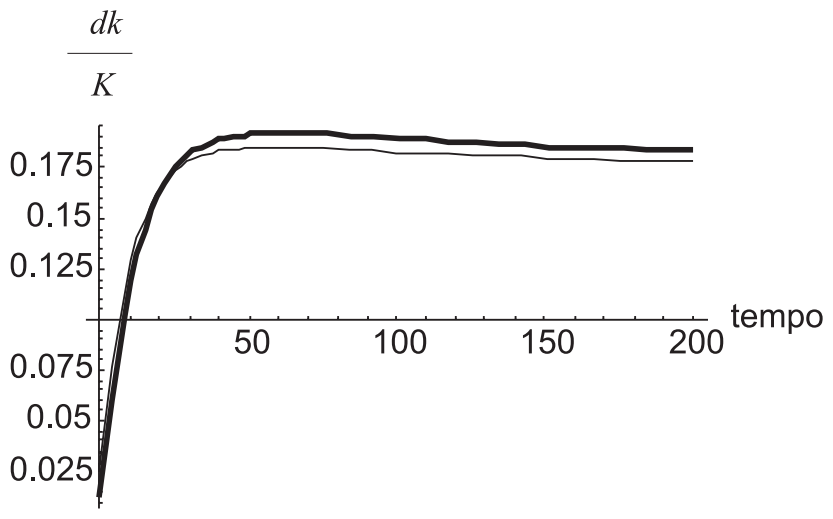


Com relação a sua trajetória dinâmica, verifica-se que o impacto inicial do progresso tecnológico comprime o grau de utilização da capacidade, mas posteriormente (depois do décimo oitavo período) o grau de utilização passa a apresentar uma trajetória nitidamente mais elevada do que a existente antes do choque. De fato, o valor de equilíbrio da trajetória anterior de $73,53 \%$ passa agora, após ter ocorrido o choque tecnológico, para $75,87 \%$.

A dinâmica da taxa de investimento também sofre variações em decorrência da sensibilidade do parâmetro tecnológico. Com efeito, o valor inicial da taxa de investimento, que antes era de $2,53 \%$ passa agora, após o choque tecnológico, para $1,21 \%$, apresentando uma diminuição de $1,32 \%$. Com relação a sua trajetória, percebe-se que inicialmente a taxa de investimento assume valores abaixo da trajetória padrão. No entanto, depois do vigésimo sétimo período, a nova trajetória gerada pelo choque assume valores superiores ao da trajetória padrão. Em termos numéricos, o novo valor de equilíbrio da taxa de investimento passa a ser aproximadamente de $17,97 \%$ contra um valor antigo de $17,89 \%$, mostrando dessa forma a pouca sensibilidade da taxa de investimento com relação ao parâmetro de sensibilidade tecnológica.

As taxas de lucro e de juros bancários evidenciam suas trajetórias por meio da Figura 4. Observando primeiramente a taxa de lucro, vemos que o choque tecnológico desloca o valor inicial de $3,16 \%$, correspondente à dinâmica padrão, para $1,51 \%$ correspondente à nova dinâmica. Ademais, o comportamento da taxa de lucro mostra que, inicialmente, o aumento da sensibilidade do parâmetro tecnológico gera uma trajetória da taxa de lucro menor do que a trajetória existente antes do choque.

Porém, no período 27 ocorre uma inversão entre as duas trajetórias, passando agora a taxa de lucro pós-choque tecnológico a descrever uma dinâmica que a faz atingir um valor de equilíbrio de longo prazo equivalente a 31,09\% acima do valor de equilíbrio da sua trajetória padrão, igual a $22,36 \%$. Assim, percebe-se que a sensibilidade da taxa de lucro com relação a mudanças tecnológicas é bastante elevada, sendo a elasticidade da taxa de lucro com relação ao progresso tecnológico igual a 1,3.

Ainda com relação à Figura 4, percebe-se que a taxa de juros bancários tem o seu valor inicial deslocado em decorrência do choque tecnológico de $24,96 \%$ para $19,75 \%$. Não obstante esse deslocamento, no longo prazo a nova trajetória da taxa de juros converge para um valor de equilíbrio de longo prazo muito semelhante ao anterior, assumindo o valor de $2,11 \%$ em contraste com o valor de $2,22 \%$ da trajetória padrão, com uma diminuição de $-0,95 \%$ entre um valor e outro. 
FIGURA 4 - IMPACTO DOS CHOQUES TECNOLÓGICOS SOBRE $(r)$ E $(i)$

(A) TAXA DE LUCRO $(r)$ QUANDO $(\psi=0,03)$ e $\underbrace{(\psi=0,04)}_{\text {"NEGRITO" }}$

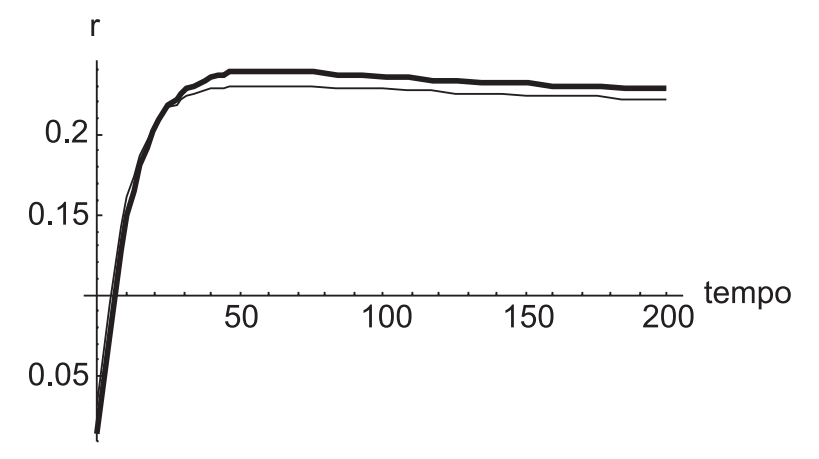

(B) TAXA DE JUROS BANCÁRIOS $(i)$ QUANDO $(\psi=0,03)$ e $\underbrace{(\psi=0,04)}_{\text {"NEGRITO" }}$

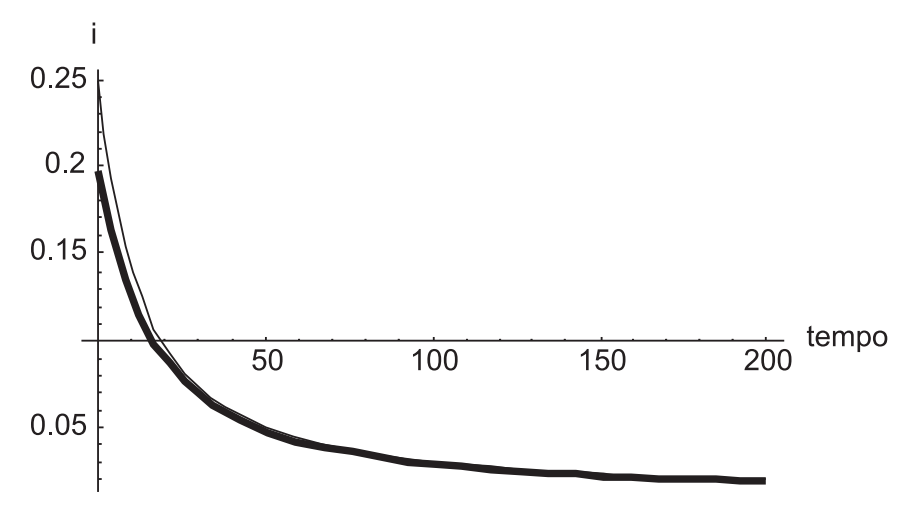

Aqui se percebe com certa clareza as inter-relações que existem na dinâmica em estudo. De acordo com as equações (17) e (19), um choque tecnológico representado pelo aumento de $\psi$ elevaria a taxa de inovação tecnológica $\hat{\Gamma}$ e, conseqüentemente, a taxa de juros bancária $i$. Porém, os resultados da simulação sugerem que este efeito é compensado pela diminuição dos salários reais $W / P$ causada pelo aumento de preços $P$. Esta diminuição dos salários reais diminui, por conseguinte, a parcela dos salários na renda $\sigma$, e através da conseqüente diminuição da taxa de inovação tecnológica $\hat{\Gamma}$, leva à queda da taxa de juros bancária $i$. 
A análise acima realizada está sistematizada na Tabela 3. Por essa tabela vê-se que todas as macrovariáveis são inelásticas com relação ao parâmetro de sensibilidade do progresso tecnológico, com exceção da taxa de lucro que apresenta uma elasticidade de 1,3 .

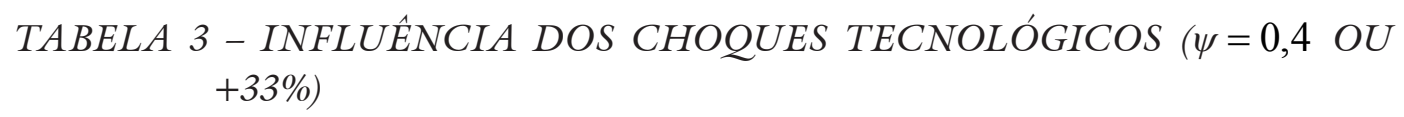

\begin{tabular}{lrrrr}
\hline Variável & \multicolumn{1}{c}{ c } & \multicolumn{1}{c}{$r / K$} & \multicolumn{1}{c}{$i$} \\
\hline Valores Padrão & 0,7353 & 0,1789 & 0,2236 & 0,0222 \\
Valores Finais & 0,7587 & 0,1847 & 0,3209 & 0,0211 \\
Variação Percentual & $3,18 \%$ & $3,24 \%$ & $43,51 \%$ & $-0,95 \%$ \\
Elasticidade & $<1$ & $<1$ & $>1$ & $<1$ \\
\hline \hline
\end{tabular}

Ademais, percebe-se pela Tabela 3 que o grau de utilização da capacidade $u$, a taxa de investimento $I / K$ e a taxa de lucro $r$ são positivamente correlacionados com o parâmetro de sensibilidade tecnológico $\psi$, enquanto a taxa de juros bancários $i$ apresenta uma correlação negativa com relação a esse parâmetro.

\section{TESTE DE IMPULSO-RESPOSTA: A INFLUENNCIA DA PROPENSÃO A POUPAR DOS CAPITALISTAS}

O segundo e último experimento consiste em analisar os efeitos do aumento de $1 \%$ na propensão a poupar dos capitalistas. Tal aumento pode ser visto, dentre outros fatores, como uma ação defensiva dos capitalistas frente a um aumento da incerteza, ou seja, como uma proxy do grau de confiança dos capitalistas com relação ao futuro da economia.

A Figura 5 mostra a influência do aumento em $1 \%$ da propensão a poupar sobre o grau de utilização da capacidade e a taxa de investimento. Tal aumento faz com que o valor inicial do grau de utilização da capacidade apresente um deslocamento para baixo, saindo do nível padrão de 37,96\% e indo para 35,90\%. Percebe-se também que na fase inicial (até o décimo período) praticamente não há diferença entre a trajetória do grau de utilização padrão e a trajetória originária da maior propensão a poupar. Porém, após esse período, quando o grau de utilização atinge $76,45 \%$ da sua capacidade produtiva, as duas trajetórias passam a divergir. 
Com efeito, a trajetória que descreve a dinâmica do grau de utilização quando a propensão a poupar é mais elevada atinge seu valor máximo em torno de $83,75 \%$ (ao contrário de $93,87 \%$ da situação padrão) e, depois, decresce monotonicamente até seu novo valor de equilíbrio de longo prazo equivalente a $65,43 \%$. Como o valor de equilíbrio padrão se encontrava fixado em $73,53 \%$, conclui-se que o aumento de $1 \%$ na propensão a poupar gerou uma diminuição de $11,02 \%$ no grau de utilização da capacidade.

FIGURA 5 - A INFLUENCIA DA PROPENSÃO A POUPAR SOBRE (u) E $(g \equiv d K / K)$

A) GRAU DE UTILIZAÇÃO DA CAPACIDADE (u) QUANDO $(s=0,8) \mathrm{e}$ $\underbrace{(s=0,808)}_{\text {"NEGRITO" }}$

$\mathrm{U}$

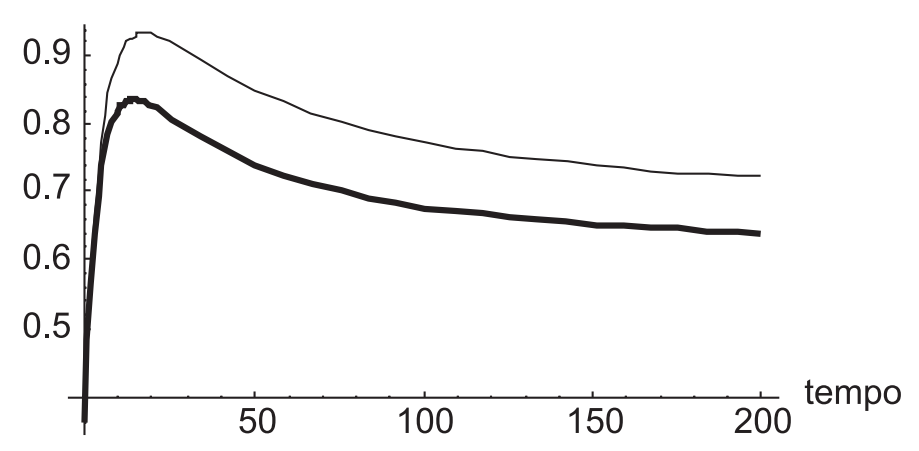

(B) TAXA DE INVESTIMENTO $(g \equiv d K / K)$ QUANDO $(s=0,8)$ e $\underbrace{(s=0,808)}_{\text {"NEGRITO" }}$

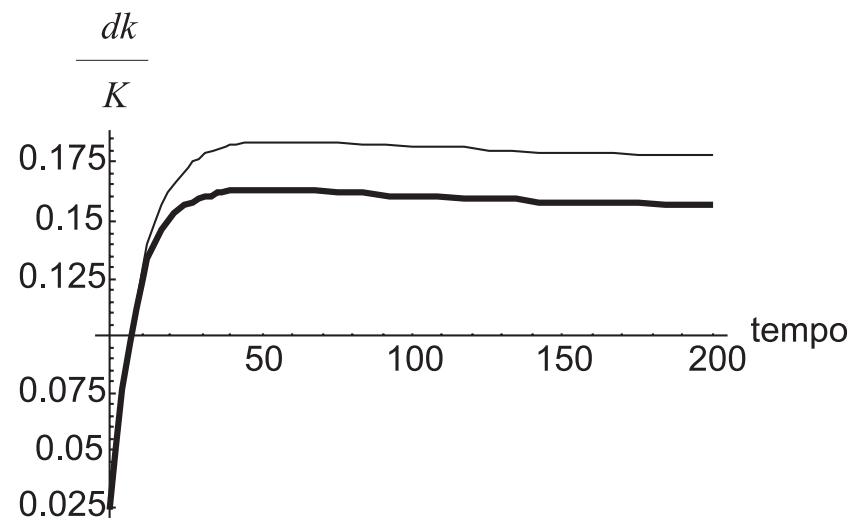


Por sua vez, a dinâmica da taxa de investimento descrita pela Figura 5 mostra que o aumento da propensão a poupar teve um efeito leve sobre o valor inicial da taxa de investimento, que passou do valor padrão correspondente a $2,53 \%$ para o novo valor igual a $2,42 \%$. Além disso, a trajetória da taxa de investimento foi inicialmente pouco afetada pelo aumento da propensão a poupar; no entanto, após o décimo primeiro período, as duas dinâmicas passam a divergir. De fato, o novo valor de equilíbrio para a taxa de investimento depois do aumento da propensão a poupar passa a ser de $15,85 \%$, bem menor quando comparado com o valor padrão (correspondente com uma menor propensão a poupar) de $17,89 \%$.

A Figura 6 descreve a dinâmica da taxa de lucro e da taxa de juros bancários antes e depois do aumento de $1 \%$ da propensão a poupar dos capitalistas. Assim, o aumento da propensão a poupar reduz o valor inicial da taxa de lucro de 3,63\% antes da mudança, para 2,99\% depois da mudança. Verifica-se, também, que os comportamentos das duas trajetórias da taxa de lucro permanecem semelhantes até o décimo período, quando então passa a descrever uma dinâmica significativamente mais baixa do que a padrão. Ou seja, o aumento da propensão a poupar implicou uma drástica redução na taxa de lucro de longo prazo dos capitalistas. Com efeito, o valor de equilíbrio de longo prazo reduz do patamar padrão de $22,36 \%$ para $19,62 \%$.

FIGURA 6 - A INFLUENCIA DA PROPENSÃO A POUPAR SOBRE $(r) E(i)$

(A) TAXA DE LUCRO $(r)$ QUANDO $(s=0,8)$ E $\underbrace{(s=0,808)}_{\text {"NEGRITO" }}$

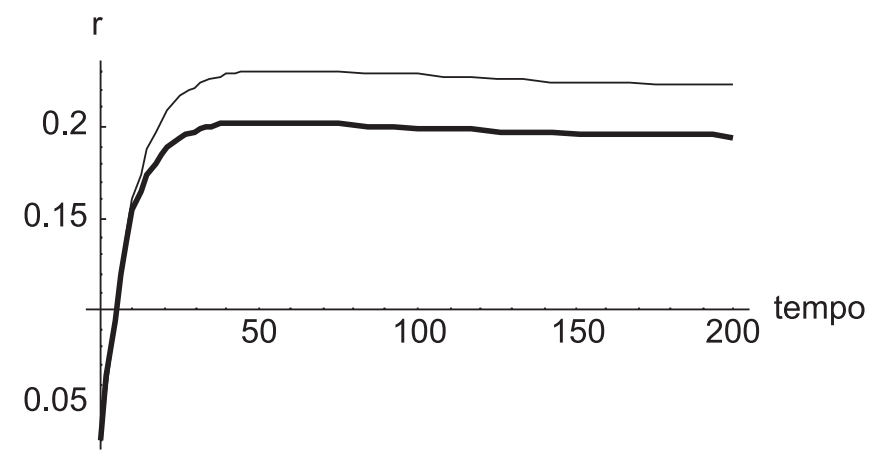


(B) TAXA DE JUROS BANCÁRIOS (i) QUANDO $(s=0,8)$ E $\underbrace{(s=0,808)}_{\text {"NEGRITO" }}$

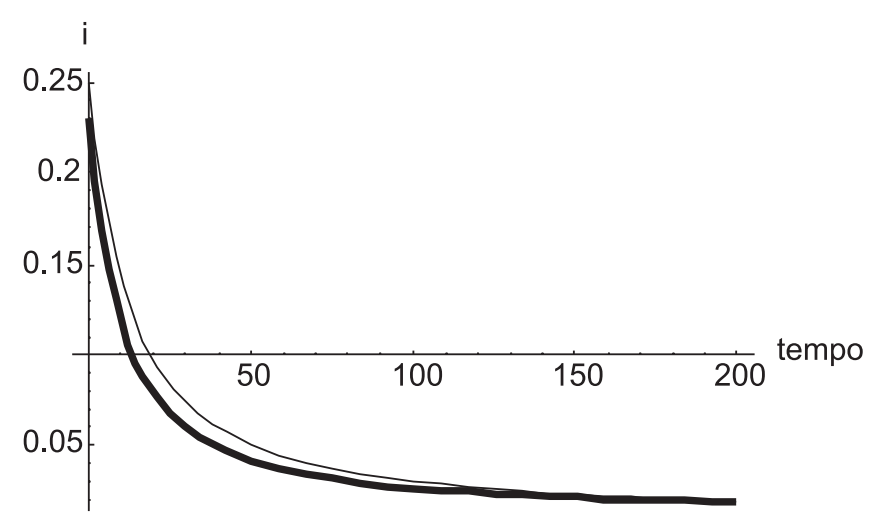

A taxa de juros bancária, depois do aumento da propensão a poupar, assume desde o início uma trajetória diversa da trajetória padrão. O seu valor inicial cai de $24,96 \%$ para $23,00 \%$ após a mudança na propensão e, com o passar do tempo, passa a descrever uma trajetória monotonicamente decrescente e continuamente menor do que a padrão. Embora no longo prazo, elas convergem para valores praticamente iguais, correspondente a aproximadamente $2,22 \%$.

A Tabela 4 a seguir sintetiza a discussão feita com relação ao impacto no aumento da propensão a poupar sobre a dinâmica das principais macrovariáveis em estudo. Por ela, percebe-se que a elasticidade da propensão a poupar sobre todas as variáveis econômicas estudadas é maior do que a unidade. Na realidade, o aumento de $1 \%$ na propensão a poupar dos capitalistas gerou uma diminuição significativa no grau de utilização da capacidade, na taxa de investimento, na taxa de lucro e, em menor intensidade, na taxa de juros bancários.

TABELA 4-A INFLUÊNCIA DA PROPENSÃO A POUPAR $(s=0,808$ OU $+1 \%)$

\begin{tabular}{lrrrr}
\hline Variável & \multicolumn{1}{c}{$u$} & \multicolumn{1}{c}{$I / K$} & $r$ & \multicolumn{1}{c}{$i$} \\
\hline Valores Padrão & 0,7353 & 0,1789 & 0,2236 & 0,0222 \\
Valores Finais & 0,6543 & 0,1585 & 0,1962 & 0,0220 \\
Variação Percentual & $-11,02 \%$ & $-11,37 \%$ & $-12,25 \%$ & $-1,08 \%$ \\
Elasticidade & $>1$ & $>1$ & $>1$ & $>1$ \\
\hline
\end{tabular}


A análise da tabela evidencia a possibilidade teórica da existência do paradoxo da frugalidade sugerido por Keynes na Teoria Geral. Observando a Tabela 4, percebe-se que um aumento de $1 \%$ na propensão a poupar gera redução de $12,25 \%$ na taxa de lucro. Como pela equação (2l) a poupança é definida como o produto da propensão a poupar sobre a taxa de lucro, segue então que um aumento da propensão a poupar causa uma redução na poupança total.

\section{CONSIDERAÇÕES FINAIS}

O presente artigo teve como objetivo explorar os aspectos de longo prazo de um modelo macrodinâmico de integração pós-keynesiano por meio de uma análise numérica realizada através de simulação computacional. Para isso, apresentamos de forma condensada um modelo macro-dinâmico não-linear que incorpora alguns elementos centrais propugnados pela teoria pós-keynesiana, notadamente a interdependência entre os fatores reais e monetários para a determinação da dinâmica de longo prazo do sistema econômico.

O elemento central que diferencia o presente modelo de seus pares é a forma pela qual a endogenia monetária exerce sua influência sobre as macrovariáveis em estudo. Esta influência se dá por meio do aumento do custo do crédito bancário, vale dizer, da taxa de juros bancária, em decorrência da ampliação da demanda por adiantamentos para financiar inovações no processo produtivo e/ou pela intervenção da autoridade monetária visando o controle da inflação. Isto gera uma série de efeitos sobrepostos que condicionam significativamente o comportamento dinâmico de uma série de macrovariáveis-chave, como por exemplo, do grau de utilização da capacidade, da taxa de investimento, da taxa de lucro e da taxa de juros bancários.

Em busca de um conjunto plausível de parâmetros que gerassem dinâmicas e valores de equilíbrio de longo prazo condizentes com os resultados empíricos estimados para essas variáveis, determinamos uma constelação de valores paramétricos que caracteriza de maneira única a economia em estudo. De fato, a análise realizada diz respeito a uma economia com as seguintes características: baixa propensão autônoma ("animal spirits") a investir, pequena influência do progresso tecnológico sobre o investimento desejado, taxa máxima de progresso tecnológico da ordem de $3 \%$, elevado poder de monopólio das firmas, baixa taxa de crescimento populacional (1\%), taxa de juros bancária não maior do que 3,45 vezes a taxa de juros básica, grande preocupação da autoridade monetária no controle do processo inflacionário e, finalmente, baixo poder de barganha dos trabalhadores. 
Sob este conjunto de parâmetros estruturais (e comportamentais) realizaram-se dois experimentos de impulso-resposta com vistas a analisar as consequiências sobre a dinâmica econômica de um intenso choque tecnológico e de um leve aumento da incerteza representado por maior propensão a poupar dos capitalistas.

Nesse contexto, evidenciamos a possibilidade de um intenso choque tecnológico provocar, por um lado, uma leve diminuição $(-0,95 \%)$ dos valores de equilíbrio de longo prazo da taxa de juros bancários e, por outro lado, uma elevação dos valores de equilíbrio de longo prazo do grau de utilização da capacidade $(3,18 \%)$, da taxa de investimento $(3,24 \%)$ e da taxa de lucro $(43,51 \%)$. O ponto a ser ressaltado aqui é que todas as macrovariáveis, com exceção da taxa de lucro, apresentaram pouca sensibilidade com relação ao choque tecnológico enquanto para esta última a elasticidade foi significativamente maior do que um.

Por sua vez, a análise do impacto do aumento da incerteza por meio da elevação de $1 \%$ da propensão a poupar dos capitalistas mostrou que as macrovariáveis em estudo são significativamente elásticas com relação à propensão a poupar dos capitalistas, com exceção da taxa de juros que apresentou uma elasticidade muito próxima da unitária. Ademais, os resultados mostraram que o aumento da propensão a poupar (proxy para a incerteza) diminuiu o grau de utilização da capacidade $(-11,02 \%)$, a taxa de investimento (-11,37\%), a taxa de lucro $(-12,25 \%)$ e a taxa de juros $(-1,08 \%)$, evidenciando dessa forma o alto impacto sobre as macrovariáveis reais e o baixo impacto sobre a macrovariável monetária, apesar desta sofrer uma significativa diminuição no curto prazo.

Os resultados da simulação evidenciam também a existência do paradoxo da frugalidade no qual um aumento da propensão a poupar dos indivíduos provoca a diminuição do nível de poupança agregada. No presente caso, o aumento de $1 \%$ na propensão a poupar dos capitalistas causou uma significativa queda na taxa de lucro $(-12,25 \%)$, o que implicou a redução da poupança agregada.

Por fim, os exercícios de dinâmica comparativa sugerem que para uma economia desta natureza é mais importante a manutenção da estabilidade macroeconômica, que garanta uma baixa propensão marginal a poupar, do que o incentivo ao aumento da produtividade, embora os resultados sejam aparentemente fortes, pois mostram que ambos os efeitos - elevado progresso tecnológico e baixa propensão a poupar - são benéficos para a sociedade. 


\section{ANEXO I}

Derivando as equações diferenciais $(30)$ e (31) com relação à parcela salarial $\sigma$ e o estoque de capital em unidades de trabalho eficiente $k$, e efetuando as substituições necessárias, obtém-se a seguinte matriz Jacobiana $|J|$ :

$$
\begin{aligned}
& J_{11} \equiv \partial \hat{\sigma} / \partial \sigma=\left(\partial u^{*} / \partial \sigma\right)(\lambda \varepsilon \cdot k-\rho \phi)-(\lambda+\psi+\rho) \\
& J_{12} \equiv \partial \hat{\sigma} / \partial k=\lambda \varepsilon \cdot u^{*}>0 \\
& J_{21} \equiv \partial \hat{k} / \partial \sigma=\left[\partial\left(I^{*} / K\right) / \partial \sigma\right]+\psi \\
& J_{22} \equiv \partial \hat{k} / \partial k=0
\end{aligned}
$$

Os elementos $J 12$ e $J 22$ dessa matriz Jacobiana $|J|$ são claramente não-negativos. Com efeito, as configurações de equilíbrio e o comportamento dinâmico do sistema dependem dos valores dos elementos $J 12$ e $J 22$.

Desse modo, existem diversas configurações possíveis que geram algum tipo de equilíbrio no espaço $(k-\sigma)$. A Tabela 5 a seguir evidencia as condições necessárias e suficientes para que haja um equilíbrio instável, do tipo ponto de sela, na Região PL (Profit-led), e um equilíbrio estável, baseado em espirais amortecidas, na Região WL (Wage-Led). 
TABELA 5 - CONDIÇÓES PARAMÉTRICAS PARA O EQUILÍBRIO

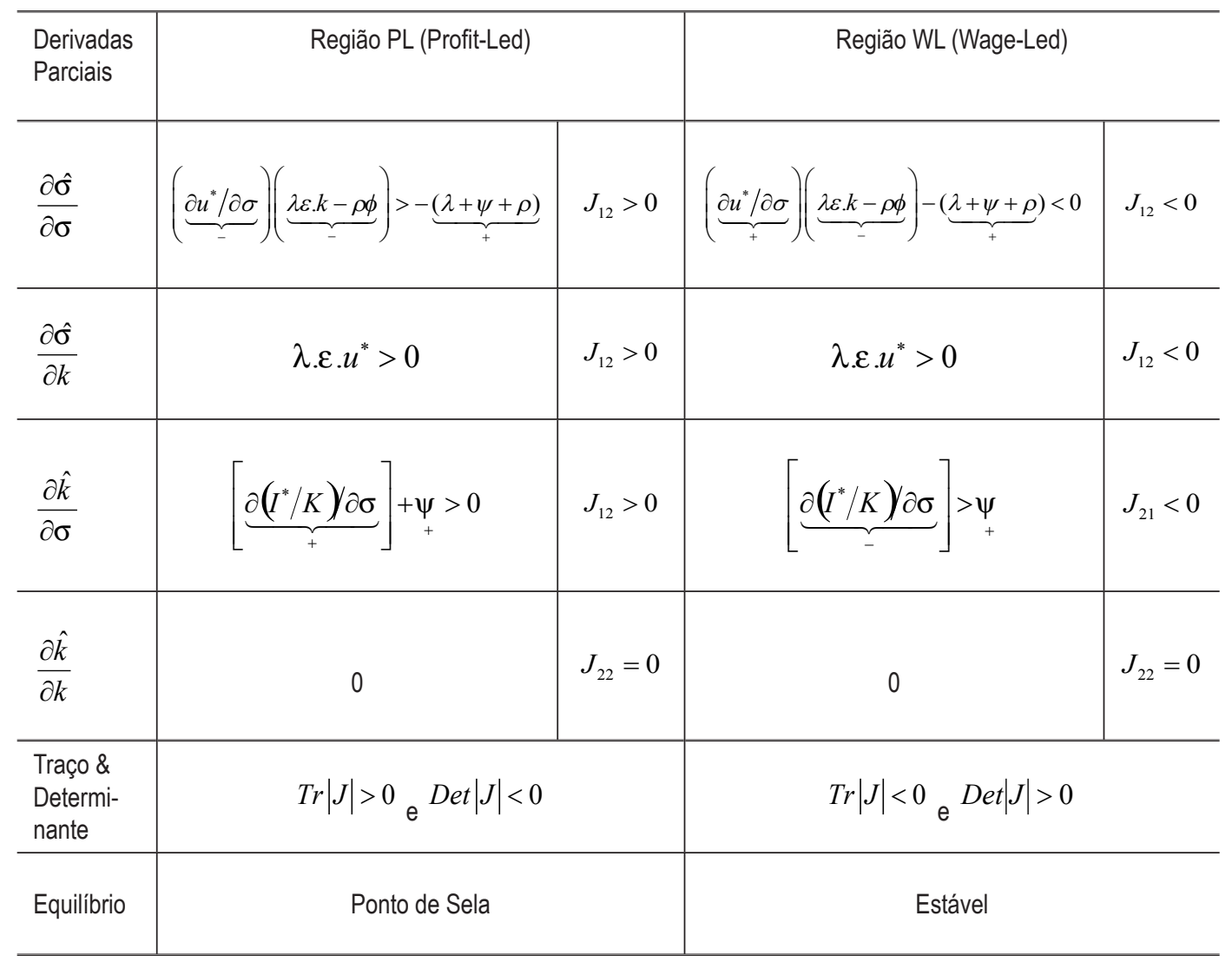

Igualando a taxa de crescimento proporcional da parcela salarial a zero e aplicando a derivada total à expressão resultante, chega-se à seguinte equação: $\frac{\partial k}{\partial \sigma}=\frac{[\rho \phi-(\lambda \varepsilon) \cdot k] \cdot\left(\partial u^{*} / \partial \sigma\right)+(\lambda+\psi+\rho)}{u^{*} \lambda \varepsilon}$. Como esta equação depende da derivada parcial $\partial u^{*} / \partial \sigma$, e esta é uma função quadrática da parcela salarial, existem até duas raízes reais que satisfazem à equação, quando se considera o lócus $\hat{\sigma}=0$. Por sua vez, a equação (31) é cúbica na parcela salarial. No entanto, apenas duas das três raízes possíveis do lócus $\hat{k}=0$ assumem valores positivos. Sendo assim, a Figura 7 mostra a configuração de equilíbrio resultante da Tabela 5 .

O diagrama de fases da Figura 7 foi dividido em duas regiões, região PL (Profit-Led) e WL (Wage-Led). Na região PL prevalece um equilíbrio instável do tipo ponto de sela, enquanto na região WL prevalece um equilíbrio estável baseado em espirais amortecidas. Ademais, qualquer trajetória que parta de dentro do espaço delimitado pela 
órbita que se inicia no ponto A (trajetória de sela), convergirá por meio de flutuações amortecidas ao ponto de equilíbrio $E_{2}$.

FIGURA 7 - EQUILÍBRIOS MÚLTIPLOS E TRAJETÓRIA AMORTECIDA

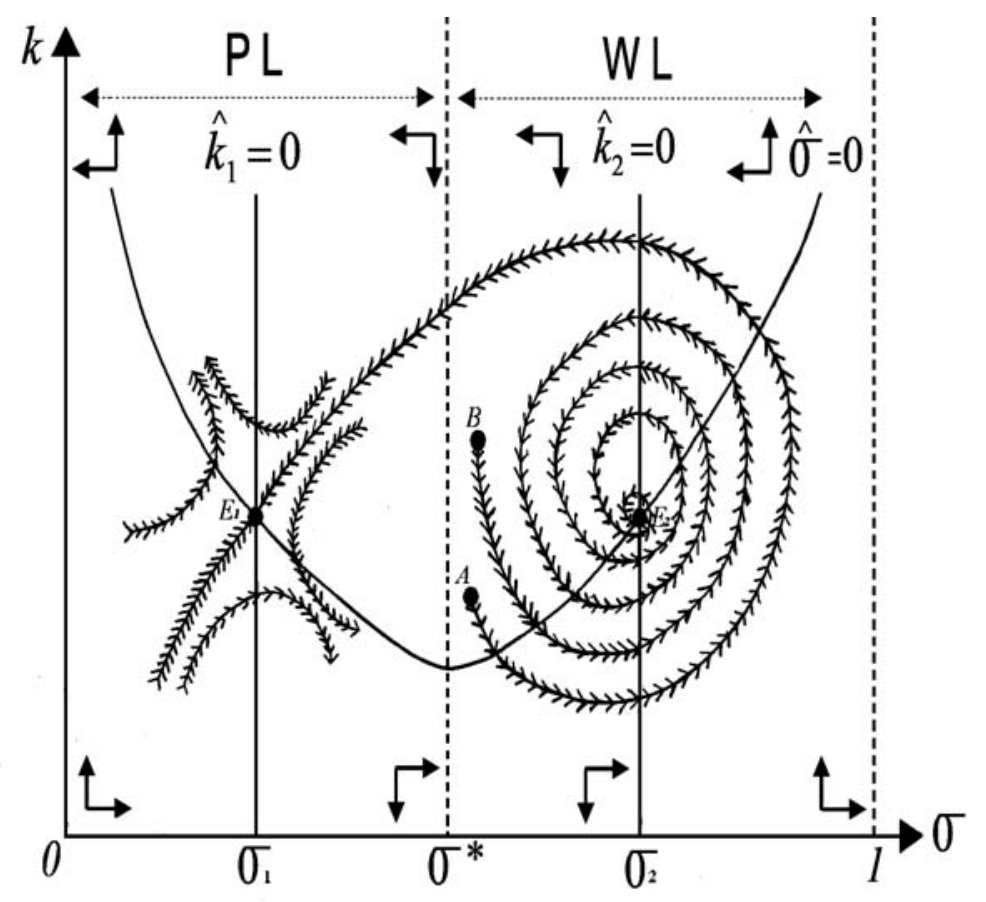

ANEXO II

Devido à natureza não-linear do modelo, a sua dinâmica é sensível às condições iniciais. Dito de outra forma, as trajetórias e as condições de equilíbrio do modelo são sensíveis ao seu passado, vale dizer, à sua história. Com efeito, exploramos na Tabela 6 a seguir a sensibilidade das macrovariáveis em estudo diante de mudanças nas condiçôes iniciais do modelo.

A Tabela 6 mostra que, apesar da dinâmica do modelo ser sensível às condições iniciais, essa sensibilidade não é extrema, uma vez que os valores de equilíbrio de longo prazo variaram relativamente pouco com as mudanças nas condiçôes iniciais. 
TABELA 6 - INFLUENNCIA DAS CONDIÇÕES INICIAIS

\begin{tabular}{|c|c|c|c|c|c|}
\hline \multicolumn{2}{|c|}{ Condições Iniciais } & \multicolumn{4}{|c|}{ Valor do Equilíbrio de Longo Prazo } \\
\hline$k[0]$ & $\sigma[0]$ & $u$ & $I / K$ & $r$ & $i$ \\
\hline 0,50 & 0,75 & 0,7219 & 0,1775 & 0,2215 & 0,0197 \\
\hline 0,50 & 0,65 & 0,7213 & $0,1745^{*}$ & 0,2218 & 0,0196 \\
\hline 0,50 & 0,80 & 0,7222 & 0,1775 & 0,2219 & 0,0197 \\
\hline 0,45 & 0,75 & 0,7217 & 0,1775 & 0,2218 & 0,0196 \\
\hline 0,55 & 0,75 & 0,7224 & $0,1776^{* *}$ & 0,2219 & 0,0197 \\
\hline 0,10 & 0,10 & $0,6986^{*}$ & 0,1748 & 0,2185 & $0,0155^{*}$ \\
\hline 0,90 & 0,90 & $0,7247^{\star *}$ & 0,1778 & $0,2223^{* *}$ & $0,0202^{* *}$ \\
\hline 0,10 & 0,90 & 0,7208 & 0,1774 & 0,2218 & 0,0195 \\
\hline 0,90 & 0,10 & 0,7025 & 0,1753 & $0,2191^{*}$ & 0,0162 \\
\hline
\end{tabular}

Legenda: * Valores mínimos; **Valores máximos.

\section{REFEREANCIAS BIBLIOGRÁFICAS}

Blanchard, O. Macroeconomia: teoria e politica. $1^{\mathrm{a}}$ ed. Rio de Janeiro: Campus, 1999.

Carvalho, F. C. Moeda, produção e acumulação: uma perspectiva pós-keynesiana. In: Moedas e produção: teorias comparadas. Brasília, Unb, 1992.

Davidson, P. Money and the real word. $2^{\mathrm{a}}$ ed. Londres: MacMillan, 1978.

Dutt, A. K. Stagnation, income distribution and monopoly power. Cambridge Journal of Economics, 8, 1984.

. Accumulation, distribution and inflation in a marxian/post keynesian model with a rentier class. Review of Radical Political Economics, 21(3), p. 1826, 1989.

Growth, distribuction and uneven development. Cambridge: Cambridge University Press, 1990.

. Expectations and equilibrium: implications for Keynes, the neo-ricardian keynesians, and the post-keynesians. Journal of Post Keynesian Economics, vol. $14, \mathrm{n}^{\circ} 2,1992$.

. On the long-run stability of capitalist economies: implications of a model of growth and distribution. In: Dutt, A. K. (org.), New directions in analytical political economy. Aldershot: Edward Elgar, 1994.

; Amadeo, E. J. A post-keynesian theory of growth, interest and money. In: Baranzini; Harcourt, G. C. (Eds.). The dynamics of the wealth of nations: growth, distribution and structural change. New York: M. St. Martins's Press,1993. 
Fiocca, D. A oferta de moeda na macroeconomia keynesiana. São Paulo: Editora Paz e Terra, 2000.

Hansen, L.; Heckman, J. The empirical foundations of calibration. Journal of Economic Perspectives, v. 10, n.1, 1996.

Harrod, R. An essay in dynamic theory. Economic Joumal, v.49, mar. 1939.

Hicks, J. Mr. Keynes and the classics: a suggested interpretation. Econometrica, 1937.

Jarsulic, M. Endogenous credit and endogenous business cycle. Journal of Post Keynesian, v. 12, n. 1, p. 35-47, 1989.

Kaldor, N. Marginal productivity and the macroeconomic theories of distribution. In: Panico, Carlo; Salvadori, Neri, Post keynesian theory of growth and distribution. Cambridge: University Press, 1993.

Kalecki, M. Selected essays on the dynamics of the capitalist economy. Cambridge University Press, 1971.

Keynes, J.M. The ex-ante theory of the rate of interest. In: Moggridge, D. (Org.). The collected writings of John Maynard Keynes. Cambridge: Cambridge University Press, Vol. XIV, 1973.

Kydland, F. E.; Prescott, E. C. The computational experiment: an econometric tool. The Journal of Economic Perspectives, v. 10, n.1, winter, 1996.

Kregel, J. A. Hamlet without the prince: Cambridge macroeconomics without money. American Economic Review, 1985.

Lima, G. T. Progresso tecnológico endógeno, crescimento econômico e distribuição de renda. In: Lima, G. T; Sicsú, J.; De Paula, L. F. (orgs), Macroeconomia moderna: Keynes e a economia contemporânea. Rio de Janeiro: Campus, 1999.

; Meirelles, A. J. Mark-up bancário, conflito distributivo e utilização da capacidade produtiva: uma macrodinâmica pós-keynesiana. Revista Brasileira de Economia, Jan. - mar, 2003.

Nelson, R.; Winter, S. An evolutionary theory of economic change. Cambridge: Harvard University Press, 1982.

Pollin, R. Two theories of money supply endogeneity: some empirical evidence. Journal of Post Keynesian Economics, v. 13, n. 2, Spring, 1991.

Rowthorn, R. Demand, real wages and economic growth. Thames Papers in Political Economy. Fall, 1981.

Runde, J. Keynesian uncertainty and liquidity preference. Cambridge Journal of Economics, 18, 1994.

Risk uncertainty and bayesian decision theory: a keynesian view. In: Dow, S; Hillard, J. (org.), Keynes, knowledge and uncertainty. Edward Elgar: Aldershot, 1995. 
Samuelson, P. Fundamentos da análise econômica. São Paulo: Abril Cultural, (1983) [edição original: 1945]

Schumpeter, J. The theory of economic development. $2^{\mathrm{a}}$ ed. Nova York: Harper \& Brothers, 1934 [1912]. 1954. . History of economic analysis. Nova York: Oxford University Press,

Simon, H. A. A racionalidade do processo decisório em empresas. Ediçôes Multiplic, v. 1, n. 1, p. 25-60, 1980.

Vercelli, A. Methodological foundations of macroeconomics: Keynes and Lucas. Cambridge: Cambridge University Press, 1991.

Watanabe, K-I. An endogenous growth model with endogenous money supply: integration of post-keynesian growth models. Banca Nazionale Del Lavoro Quarterly Review, 200, mar., 1997.

You, Jong-Il. Macroeconomic structure, endogenous technical change and growth. Cambridge Journal of Economics, 18, 1994. 